\title{
Erythropoietin but not VEGF has a protective effect on auditory hair cells in the inner ear
}

\author{
Monge, A ; Gassmann, M ; Bodmer, D
}

\begin{abstract}
It has recently been shown that the oxygenregulated factors erythropoietin (Epo) and vascular endothelial growth factor (VEGF) confer protection on different cells, including neuronal-derived ones. The receptors for Epo and VEGF are widely expressed in different organs. Since mammalian auditory hair cells can irreversibly be damaged by different agents, we aimed to identify otoprotective compounds. We focused on the role of Epo and VEGF in the inner ear and review the recent studies. Epo and its receptor are expressed in the inner ear. In vitro experiments on auditory hair cells showed a protective effect of Epo in ischemia- and gentamicin-induced hair cell damage. In contrast, an in vivo study using an animal model of noise-induced hearing loss showed a negative effect of Epo. Also VEGF and its receptors are expressed in the inner ear. Changes in the expression of VEGF or its receptors have been found in the cochlea after noise exposure, transcranial vibration and diabetic or aged animals. Until now, there are no studies about a direct effect of VEGF on auditory hair cells in vitro or in vivo. We could exclude a protective effect of VEGF on gentamicininduced auditory hair cell damage in vitro. Thus, we conclude that Epo but not VEGF has a protective effect on auditory hair cell damage at least in vitro. (Part of a multiauthor review.)
\end{abstract}

DOI: https://doi.org/10.1007/s00018-009-0144-x

Posted at the Zurich Open Repository and Archive, University of Zurich

ZORA URL: https://doi.org/10.5167/uzh-24976

Journal Article

Published Version

Originally published at:

Monge, A; Gassmann, M; Bodmer, D (2009). Erythropoietin but not VEGF has a protective effect on auditory hair cells in the inner ear. Cellular and Molecular Life Sciences, 66(22):3595-3599.

DOI: https://doi.org/10.1007/s00018-009-0144-x 


\title{
Erythropoietin but not VEGF has a protective effect on auditory hair cells in the inner ear
}

\author{
Arianne Monge Naldi · Max Gassmann • \\ Daniel Bodmer
}

Received: 18 August 2009/Accepted: 20 August 2009/Published online: 10 September 2009

(c) Birkhäuser Verlag, Basel/Switzerland 2009

\begin{abstract}
It has recently been shown that the oxygenregulated factors erythropoietin (Epo) and vascular endothelial growth factor (VEGF) confer protection on different cells, including neuronal-derived ones. The receptors for Epo and VEGF are widely expressed in different organs. Since mammalian auditory hair cells can irreversibly be damaged by different agents, we aimed to identify otoprotective compounds. We focused on the role of Epo and VEGF in the inner ear and review the recent studies. Epo and its receptor are expressed in the inner ear. In vitro experiments on auditory hair cells showed a protective effect of Epo in ischemia- and gentamicin-induced hair cell damage. In contrast, an in vivo study using an animal model of noise-induced hearing loss showed a negative effect of Epo. Also VEGF and its receptors are expressed in the inner ear. Changes in the expression of VEGF or its receptors have been found in the cochlea after noise exposure, transcranial vibration and diabetic or aged animals. Until now, there are no studies about a direct effect of VEGF on auditory hair cells in vitro or in vivo. We could
\end{abstract}

\footnotetext{
A. Monge Naldi ( $\square)$

Inner Ear Research, Clinic for Otolaryngology,

Head and Neck Surgery, University Hospital Zurich,

Frauenklinikstrasse 24, NORD 2, 8091 Zurich, Switzerland

e-mail: mongearianne@hotmail.com
}

\author{
A. Monge Naldi · M. Gassmann \\ Vetsuisse Faculty, Institute of Veterinary Physiology, \\ Zurich Center for Integrative Human Physiology (ZIHP), \\ University of Zurich, Winterthurerstrasse 260, \\ 8057 Zurich, Switzerland \\ D. Bodmer \\ Inner Ear Research, Clinic for Otolaryngology, \\ University Hospital Basel, Petersgraben 4, \\ 4031 Basel, Switzerland
}

exclude a protective effect of VEGF on gentamicininduced auditory hair cell damage in vitro. Thus, we conclude that Epo but not VEGF has a protective effect on auditory hair cell damage at least in vitro. (Part of a multiauthor review.)

Keywords Apoptosis - Cochlea · Hearing · Neuroprotection - Epo receptor · VEGF receptor

\section{Introduction}

Hearing loss is one of the most relevant chronic diseases in aging. It is estimated that close to 250 million people worldwide suffer from some form of hearing impairment, and 1 of every 1,000 children is deaf by the age of 3 . The auditory (cochlear) region in the inner ear is responsible for the sense of hearing. In the organ of Corti, which is located inside the cochlea, the mechano-electrical transduction of sound takes place. The organ of Corti is composed of a single layer of approximately 3,500 inner hair cells and three rows of outer hair cells, as well as a number of different types of supporting cells. Hair cells are the most vulnerable elements in the cochlea. Their death commonly occurs following acoustic trauma or exposure to ototoxins, such as aminoglycoside antibiotics and cisplatin. Since these hair cells do not regenerate, their damage leads to a lifelong hearing impairment and thus represents the most common cause of permanent hearing loss.

It appears that hair cell death occurs via an apoptotic process [1]. The mechanisms of sensory hair cell degeneration in response to different ototoxic stimuli share a final common pathway: the caspase activation [2]. Currently, the only effective clinical intervention is prevention from exposure to known ototoxic insults. Potential causally 
based therapies have yet to emerge. At present, there is great interest in finding otoprotective compounds.

Oxygen homeostasis in mammals is controlled through respiratory and cardiac responses. The key factors in hypoxia-induced pathways are the hypoxia-induced factors (HIFs). An extensive review on oxygen sensing and HIFs by Webb et al. can be found in this issue. In short, under hypoxic conditions, prolyl-hydroxylase domain and factorinhibiting HIF1 hydroxylases are inactive. The alpha subunit of HIF is stable under hypoxia and translocates into the cell nucleus where it binds to the HIF beta subunit, which is oxygen independent. HIF then binds to target genes through a recognition DNA sequence (hypoxic response elements, HRE). Interaction with the co-activator $\mathrm{CBP} / \mathrm{p} 300$ induces or represses a large number of genes. These are genes of erythropoiesis and iron metabolism [erythropoietin (Epo), transferrin, transferrin-receptor, etc.], genes of vascular regulation [vascular endothelial growth factor (VEGF) and its receptor 1, i-NOS, heme oxygenase 1, etc.], genes of glucose uptake and glycolysis (glucose transporter1, GAPDH, etc.) and genes of apoptosis (BNIP3). At least 100 HIF-dependent genes have been recognized [3-5].

In the last years it has been shown that oxygen-regulated factors such as Epo and VEGF confer protection on different cells, including neuronal-derived ones. Their neuroprotective effects involve suppression of cell death pathways mediated by activation of antiapoptotic proteins through the transcription factor $\mathrm{NF} \kappa \mathrm{B}$ and inhibiting proapoptotic signaling by BAD, caspases and other effectors $[6,7]$. Here we will review the role of Epo and VEGF as a possible protective factor in the inner ear.

\section{Erythropoietin}

\section{Erythropoietin and neuroprotection}

Epo is a glycoprotein hormone that is manly produced in the fetal liver and adult kidney and promotes survival, proliferation and differentiation of erythroid progenitor cells. Binding of Epo to the Epo receptor represses apoptosis and allows the final maturation of erythroid progenitor cells to erythrocytes [8]. New studies found that many other organs, including the central nervous system [9] and the retina [10], also express Epo and its receptor. In the central nervous system, Epo has neuroprotective, neurotrophic and anti-inflammatory properties, and it influences the neurogenesis, angiogenesis and the vascular permeability induced by VEGF [11]. In vivo, Epo has been tested as a potential therapeutic cytokine in several animal models including stroke, multiple sclerosis, schizophrenia, Parkinson's disease, epilepsy, brain trauma and spinal cord injury [11]. In clinical studies, Epo has improved patients' functional outcome in the Göttingen-Epo-Stroke study [12]. A multicenter phase II/III trial is being conducted [13, 14]. A phase II trial demonstrated an improvement of schizophrenia-related cognitive performance of chronic schizophrenic patients by Epo add-on medicamentation [15]. Also in retinopathies, such as models of glaucoma [16, 17], age-related macular degeneration and retinitis pigmentosa [10], Epo has protective effects.

\section{Erythropoietin in the cochlea}

Recently, the effect of Epo in the inner ear was tested in different studies. Cayé-Thomasen et al. [18] found for the first time expression of Epo and its receptor in the inner ear. Epo expression was exclusively found in the supporting cells of the organ of Corti. In the rest of the cochlea, spiral ligament fibrocytes, some cells of the stria vascularis and endothelial cells expressed Epo receptor in guinea pig. Our study showed expression of Epo receptor also in auditory hair cells and supporting cells of the organ of Corti in newborn and adults rats [19].

A direct effect of Epo in vitro on auditory hair cells was tested by two different studies using explant cultures of the rat organ of Corti. The first study showed a protective effect of Epo in ischemia-induced damage [20], while in the second study we demonstrated a dose-dependent protective effect against gentamicin-induced hair cell damage [19]. However, in both studies only a partial effect was observed compared to untreated control explants. A toxic effect of Epo itself was excluded.

The first in vivo study using an animal model of noiseinduced hearing loss showed a negative effect of Epo [21]. In the first trial guinea pigs were treated with Epo to the round window membrane $24 \mathrm{~h}$ after noise exposure either by pump for a week or by single dose in the middle ear. No improvement of hearing occurred in any group. In the second trial rats had a single dose Epo 1 or $14 \mathrm{~h}$ after noise exposure. After 8 days in both groups, the hearing had partly recovered, whereas the hearing loss of Epo-treated animals was significantly worse than in controls. In the third trial, rats were injected with Epo intraperitoneally $1 \mathrm{~h}$ before noise exposure. The hearing of the Epo-treated animals was significantly worse than controls [21]. The authors of that study suggest that Epo mediates a vasoconstrictive effect in part through the same pathways activating vasoconstriction during noise exposure. This may lead to a synergistic reduction of cochlear blood flow and an increase of the hearing loss when treating rats with Epo and exposing them to noise as rats are known to be more sensitive to a decrease in blood flow during noise exposure [21, 22]. Finally, a study with end-stage renal failure patients had a significant improvement of hearing after treatment with Epo $120 \mathrm{U} / \mathrm{kg}$ per week for 5-8 months. However, this effect 
could be due to the improvement of anemia or due to a direct effect of Epo in the inner ear itself [23].

\section{VEGF}

VEGF and neuroprotection

VEGF was first discovered as the vascular permeability factor [24]. Shortly thereafter, VEGF was also isolated as an angiogenic factor that stimulates endothelial cells to proliferate, migrate and survive in a serum-poor environment [25]. In addition to a cellular role for VEGF in regulating proliferation, migration, permeability and acting as an antiapoptotic molecule, recently neuroprotective properties were found. In vitro, VEGF has a direct effect on cultured motor neurons protecting them from toxicity due to hypoxia, increased reactive oxygen species, serum deprivation and glutamate-induced exocitotoxicity [26]. In vivo, VEGF is expressed in the spinal cord neurons and astrocytes, which signal trough VEGFR-2 and neuropilin-1 located on motor neurons and peripheral nerve axons [26]. Recent work revealed a role for reduced VEGF expression in the pathogenesis of amyotrophic lateral sclerosis [27]. VEGF also has an important role in visual function [28].

\section{VEGF in the cochlea}

VEGF and VEGF-1 and VEGF-2 receptors have been found in different cell types in the cochlea, for example, in the organ of Corti in Deiters cells, pillar cells, inner and outer hair cells [29-31]. A recent study comparing the alterations of VEGF and the VEGF-receptors after noise exposure postulated that modulation of VEGF and its receptors may be part of a neuroprotective mechanism in response to noise [31]. Other studies showed reduced VEGF-expression in the cochlea and in the stria vascularis of aged animals [32], VEGF and VEGF-R2 expression was induced in the cochlea by transcranial vibration [33], and in noise-exposed animals an increase in VEGF was found [34]. Recently, an increased cochlear expression of VEGF, iNOS and eNOS was detected in the diabetic rat, suggesting that this upregulation may be involved in the pathogenesis of cochlea functional loss [35]. We tested the effect of VEGF on gentamicin-induced hair cell loss in vitro following an earlier protocol [19] (Fig. 1). A direct toxic effect of VEGF on auditory hair cells could be excluded. Quantitative analysis of surviving outer hair cells showed no statistically significant reduction of gentamicininduced hair cell loss in organs of Corti treated with VEGF and gentamicin compared to gentamicin control treatment only. Thus, we exclude a protective effect of VEGF under these conditions in vitro.

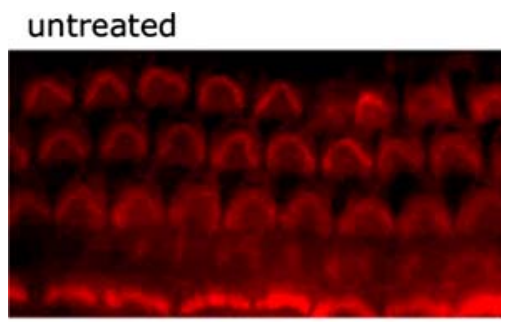

$3 \mathrm{mM}$ gentamicin

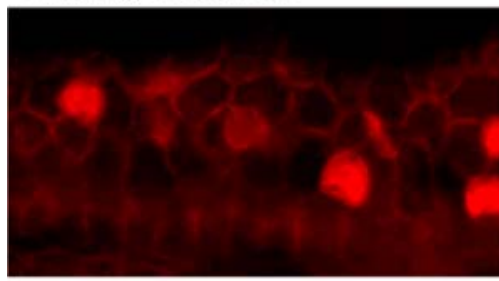

gentamicin and VEGF

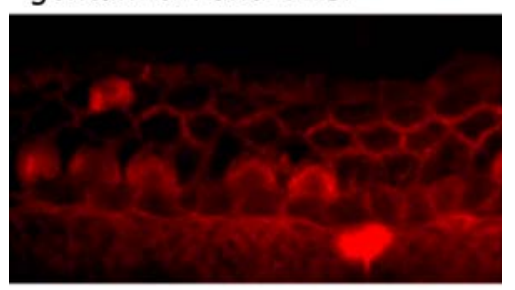

gentamicin and EPO

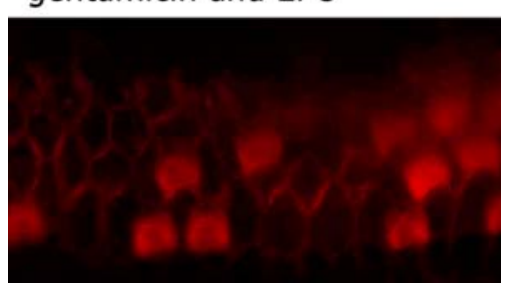

Fig. 1 Effect of VEGF on gentamicin-induced hair cell damage. Representative photographs of organs of Corti labeled with Texas Red $\mathrm{X}$-phalloidin are shown. Untreated organs of Corti demonstrate three orderly rows of outer hair cells and a single row of inner hair cells. To induce severe hair cell damage, organs of Corti were cultured in cell culture medium supplemented with gentamicin [19]. Organs of Corti were pre-treated for $2 \mathrm{~h}$ with increasing concentrations of VEGF (50, 100 and $300 \mathrm{ng} / \mathrm{ml}$ ) [36] and exposed to VEGF and gentamicin for an additional $24 \mathrm{~h}$. Culture with VEGF in addition to gentamicin did not decrease hair cell loss compared to gentamicin treatment only. In contrast to VEGF, Epo showed a dose-dependent protective effect on gentamicin-induced hair cell damage in vitro [19]

\section{Conclusions and outlook}

Epo and VEGF are hypoxically regulated genes. In the last years, a direct neuroprotective effect for Epo and VEGF could be shown [6,7]. Both factors act by binding to specific receptors, Epo binds to the Epo-receptor, and VEGF binds to the VEGF-1 and VEGF-2-receptors. In the cochlea Epo and its receptor as well as VEGF and its receptors have been detected. As we showed previously, significantly less hair cell loss occurred in the organs of 
Corti that were pretreated with $0.1 \mathrm{U} / \mathrm{ml}$ Epo as compared with samples treated with gentamicin only in vitro [19]. Another study proved a protective effect of Epo in ischemia-induced damage in vitro [20]. However, an in vivo study of noise-induced hearing loss showed a negative effect of Epo. In our results we did not find a significant reduction of auditory hair cell loss in conditions where the organs of Corti were co-cultured with VEGF and gentamicin compared to gentamicin control treatment in vitro. Of note, we investigated for the first time the effect of VEGF on gentamicin-damaged hair cells, and our in vitro data are limited to 6-day-old rats, but they provide evidence that VEGF is not able to protect auditory hair cells from gentamicin-induced hair cell damage. Up to now, the role of Epo and VEGF in the inner ear is still unclear. However, we do not exclude the possibility that Epo and VEGF protect auditory hair cells from other types of damage, such as hypoxia, aging or different drugs in vivo. Thus, future studies are needed to clarify if Epo and VEGF have otoprotective effects.

Conflict of interest statement The authors declare that they have no competing financial interests.

\section{References}

1. Li L, Nevill G, Forge A (1995) Two modes of hair cell loss from the vestibular sensory epithelia of the guinea pig inner ear. J Comp Neurol 355:405-417

2. Cheng AG, Cunningham LL, Rubel EW (2005) Mechanisms of hair cell death and protection. Curr Opin Otolaryngol. Head Neck Surg 13:34334-34338

3. Brahimi-Horn C, Pouysségur J (2006) The role of the hypoxiainducible factor in tumor metabolism growth and invasion. Bull Cancer 93:E73-E80

4. Fandrey J, Gorr TA, Gassmann M (2006) Regulating cellular oxygen sensing by hydroxylation. Cardiovascular Res 71(4):642651

5. Höpfl G, Ogunshola O, Gassmann M (2004) HIFs and tumors: causes and consequences. Am J Physiol 286:R608-R623

6. Noguchi CT, Asavaritikrai P, Teng R, Jia Y (2007) Role of erythropoietin in the brain. Crit Rev Oncol Hematol 64:157-159

7. Góra-Kupilas K, Jośko J (2005) The neuroprotective function of vascular endothelial growth factor (VEGF). Folia Neuropathol 43:31-39

8. Jelkmann W (1992) Erythropoietin: structure, control of production, and function. Physiol Rev 72:449-489

9. Buemi M, Cavallaro E, Floccari F, Sturiale A, Aloisi C, Trimarchi M, Corica F, Frisina N (2003) The pleiotropic effects of erythropoietin in the central nervous system. J Neuropathol Exp Neurol 62:228-236

10. Grimm C, Wenzel A, Groszer M, Mayser H, Seeliger M, Samardzija M, Bauer C, Gassmann M, Remé CE (2002) HIF-1induced erythropoietin in the hypoxic retina protects against light-induced retinal degeneration. Nat Med 8:718-724

11. Rabie T, Marti HH (2008) Brain protection by erythropoietin: a manifold task. Physiology (Bethesda) 23:263-274

12. Sakanaka M, Wen TC, Matsuda S, Masuda S, Morishita E, Nagao M, Sasaki R (1998) In vivo evidence that erythropoietin protects neurons from ischemic damage. Proc Natl Acad Sci USA 95:4635-4640

13. Ehrenreich H, Hasselblatt M, Dembowski C, Cepek L, Lewczuk P, Stiefel M, Rustenbeck HH, Breiter N, Jacob S, Knerlich F, Bohn M, Poser W, Rüther E, Kochen M, Gefeller O, Gleiter C, Wessel TC, De Ryck M, Itri L, Prange H, Cerami A, Brines M, Sirén AL (2002) Erythropoietin therapy for acute stroke is both safe and beneficial. Mol Med 8:495-505

14. Hasselblatt M, Ehrenreich H, Sirén AL (2006) The brain erythropoietin system and its potential for therapeutic exploitation in brain disease. J Neurosurg Anesthesiol 18:132-138

15. Ehrenreich H, Hinze-Selch D, Stawicki S, Aust C, Knolle-Veentjer S, Wilms S, Heinz G, Erdag S, Jahn H, Degner D, Ritzen M, Mohr A, Wagner M, Schneider U, Bohn M, Huber M, Czernik A, Pollmächer T, Maier W, Sirén AL, Klosterkötter J, Falkai P, Rüther E, Aldenhoff JB, Krampe H (2007) Improvement of cognitive functions in chronic schizophrenic patients by recombinant human erythropoietin. Mol Psychiatry 12:206-220

16. Junk AK, Mammis A, Savitz SI, Singh M, Roth S, Malhotra S, Rosenbaum PS, Cerami A, Brines M, Rosenbaum DM (2002) Erythropoietin administration protects retinal neurons from acute ischemia-reperfusion injury. Proc Natl Acad Sci USA 99:1065910664

17. Weishaupt JH, Rohde G, Pölking E, Siren AL, Ehrenreich H, Bähr M (2004) Effect of erythropoietin axotomy-induced apoptosis in rat retinal ganglion cells. Invest Ophthalmol Vis Sci 45:1514-1522

18. Cayé-Thomasen P, Wagner N, Lidegaard Frederiksen B, Asal K, Thomsen J (2005) Erythropoietin and erythropoietin receptor expression in the guinea pig inner ear. Hear Res 203:21-27

19. Monge A, Nagy I, Bonabi S, Schmid S, Gassmann M, Bodmer D (2006) The effect of erythropoietin on gentamicin-induced auditory hair cell loss. Laryngoscope 116:312-316

20. Andreeva N, Nyamaa A, Haupt H, Gross J, Mazurek B (2006) Recombinant human erythropoietin prevents ischemia-induced apoptosis and necrosis in explant cultures of the rat organ of Corti. Neurosci Lett 396:86-90

21. Frederiksen BL, Cayé-Thomasen P, Lund SP, Wagner N, Asal K, Olsen NV, Thomsen J (2007) Does erythropoietin augment noise induced hearing loss? Hear Res 223:129-137

22. Miller JM, Brown JN, Schacht J (2003) 8-iso-prostaglandin $\mathrm{F}$ (2alpha), a product of noise exposure, reduces inner ear blood flow. Audiol Neurootol 8:207-221

23. Shaheen FA, Mansuri NA, al-Shaikh AM, Sheikh IA, Huraib SO, al-Khader AA, Zazgornik J (1997) Reversible uremic deafness: is it correlated with the degree of anemia? Ann Otol Rhinol Laryngol 106:391-393

24. Senger DR, Galli SJ, Dvorak AM, Perruzzi CA, Harvey VS, Dvorak HF (1983) Tumor cells secrete a vascular permeability factor that promotes accumulation of ascites fluid. Science 219:983-985

25. Leung DW, Cachianes G, Kuang WJ, Goeddel DV, Ferrara N (1989) Vascular endothelial growth factor is a secreted angiogenic mitogen. Science 246:1306-1309

26. Breen EC (2007) VEGF in biological control. J Cell Biochem 102:1358-1367

27. Zachary I (2005) Neuroprotective role of vascular endothelial growth factor: signalling mechanisms, biological function, and therapeutic potential. Neurosignals 4:207-221

28. Saint-Geniez M, Maharaj AS, Walshe TE, Tucker BA, Sekiyama E, Kurihara T, Darland DC, Young MJ, D'Amore PA (2008) Endogenous VEGF is required for visual function: evidence for a survival role on müller cells and photoreceptors. PLoS ONE 3:e3554

29. Michel O, Hess A, Bloch W, Schmidt A, Stennert E, Addicks K (2001) Immunohistochemical detection of vascular endothelial 
growth factor (VEGF) and VEGF receptors Flt-1 and KDR/Flk-1 in the cochlea of guinea pigs. Hear Res 155:175-180

30. Picciotti PM, Torsello A, Cantore I, Stigliano E, Paludetti G, Wolf FI (2005) Expression of vascular endothelial growth factor and its receptors in the cochlea of various experimental animals. Acta Otolaryngol 125:1152-1157

31. Selivanova O, Heinrich UR, Brieger J, Feltens R, Mann W (2007) Fast alterations of vascular endothelial growth factor (VEGF) expression and that of its receptors (Flt-1, Flk-1 and Neuropilin) in the cochlea of guinea pigs after moderate noise exposure. Eur Arch Otorhinolaryngol 264:121-128

32. Picciotti P, Torsello A, Wolf FI, Paludetti G, Gaetani E, Pola R (2004) Age-dependent modifications of expression level of VEGF and its receptors in the inner ear. Exp Gerontol 39:1253-1258
33. Zou J, Pyykkö I, Sutinen P, Toppila E (2005) Vibration induced hearing loss in guinea pig cochlea: expression of TNF-alpha and VEGF. Hear Res 202:13-20

34. Picciotti PM, Fetoni AR, Paludetti G, Wolf FI, Torsello A, Troiani D, Ferraresi A, Pola R, Sergi B (2006) Vascular endothelial growth factor (VEGF) expression in noise-induced hearing loss. Hear Res 214:76-83

35. Liu F, Xia M, Xu A (2008) Expression of VEGF, iNOS, and eNOS is increased in cochlea of diabetic rat. Acta Otolaryngol $14: 1-9$

36. Jin KL, Mao XO, Greenberg DA (2000) Vascular endothelial growth factor: direct neuroprotective effect in in vitro ischemia. Proc Natl Acad Sci USA 97:10242-10247 